\title{
Research Paper: An Epidemiological Study of Fatal and Non-Fatal Industrial Accidents in Semnan, Iran
}

\author{
Alireza Khammar' $^{1}$ (D, Mohammad Khandan² (D), Razieh Veisi ${ }^{3}$ (D), Seyed Nouredin Hosseinighosheh ${ }^{4}$ (D), Monir Alimohammadi ${ }^{5}$ (D), Mohsen \\ Poursadeghiyan $^{6}$ (D), Seyed Habibollah Kavari ${ }^{7 *}$ (D)
}

1. Department of Occupational Health and Professional, School of Health, Zabol Medicinal Plants Research Center, Zabol University of Medical Sciences, Zabol, Iran.

2. Department of Occupational Health Engineering, School of Health, Qom University of Medical Sciences and Health Services, Qom, Iran.

3. Environmental Determinates of Health Research Center, Kermanshah University of Medical Sciences, Kermanshah, Iran.

4. Department of Occupational Health Engineering, Behbahan Faculty of Medical Sciences, Behbahan, Iran.

5. Health Management and Economics Research Center, Iran University of Medical Sciences, Tehran, Iran.

6. Research Center in Emergency and Disaster Health, University of Social Welfare and Rehabilitation Sciences, Tehran, Iran.

7. Department of Rehabilitation Sciences, University of Social Welfare and Rehabilitation Sciences, Tehran, Iran.

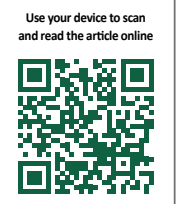

Citation Khammar A, Khandan M, Veisi R, Hosseinighosheh SN, Alimohammadi M, Poursadeghiyan M, et al. An Epidemiological Study of Fatal and Non-Fatal Industrial Accidents in Semnan, Iran. Health in Emergencies and Disasters Quarterly. 2019; 4(2):93100. http://dx.doi.org/10.32598/hdq.4.2.93

dof $\mathrm{http} / / \mathrm{dx} . \mathrm{doi} .0 \mathrm{rg} / \mathbf{1 0 . 3 2 5 9 8 / h d q . 4 . 2 . 9 3}$

\section{(1) (8)}

Article info:

Received: 25 Jul 2018

Accepted: 03 Dec 2018

Available Online: 01 Jan 2019

\section{Keywords:}

Epidemiology, Accidents, Occupational, Iran

\section{A B STRACT}

Background: Due to the importance of industrial accidents in workplaces, the current study aimed at epidemiologically investigating occupational accidents in some industrial sites in Semnan, Iran.

Materials and Methods: The current descriptive-analytical study was conducted on all accidents taking place from 2014 to 2016 in some industrial sites in Semnan. The data were extracted from the Department of Labor and Social Affairs of Semnan. SPSS software version 21 was employed to analyze data using Chi-square and logistic regression tests.

Results: The mean and standard deviation of workers age in non-fatal and fatal accidents were $30.58 \pm 16.14$ and $35.17 \pm 12.34$ years, respectively. There was no significant difference in variables such as gender, workers experience, marital status, type of industry (construction, mining, rubber, and agriculture), and educational level between fatal and non-fatal accidents $(\mathrm{P}>0.05)$. A significant relationship was observed between insurance coverage status and fatal accidents $(\mathrm{P}=0.001)$. The rate of fatal accidents was about five times more in 2015 than 2014 $(\mathrm{P}=0.01 ; \mathrm{OR}=4.76)$.

Conclusion: The rate of accidents in industrial sites can be significantly reduced by taking advantage of accident prevention programs and training courses. Occupational safety and health program can promote the performance of workers. In this regard, the development and conduction of industrial emergency plans can reduce fatal accident rates.

\footnotetext{
* Corresponding Author:

Seyed Habibollah Kavari, PhD.

Address: Department of Rehabilitation Sciences, University of Social Welfare and Rehabilitation Sciences, Tehran, Iran

E-mail: habibkavari@gmail.com
} 


\section{Introduction}

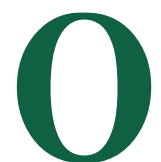

ccupational accidents in modern societies and the developing countries may impose a great cost on society $[1,2]$. European Agency for safety and health at work estimated that 4.6 million occupational events occur every year in Europe. These events may cause 146 million missing hour in workplaces [3].

Occupational events are one of the most important industrial issues [4]. Until 2008, one thousand deaths and 2000 accidents per year were reported due to occupational accidents [5]. In addition to accidents, some workers in mine, agriculture, electronic, and construction industries are exposed to occupational agents such as asbestos, silica, heavy metal fume, noise, and other hazardous agents under unfavorable working conditions [6]. Human and work ability are the main factors for accident proneness [7]. Sadeghain et al. (2013) showed that the injuries caused by electrical accidents mostly occur in the summer (33\%); however, injured workers (16.7\%) belonged to the age groups of 25-29 and 40-44 years, and no accidents were reported for workers less than 20. About $48 \%$ of the accident victims had to be hospitalized. Furthermore, $35 \%$ of the accident victims were treated in the outpatient clinics, but $7.4 \%$ died [8].

According to Unal et al. (2008) the accident and mortality rates were 12.7 and 15.6 per 100,000 workers respectively in agriculture. Moreover, $96.1 \%$ of injured persons were male. A high percentage of events happened to workers aged $25-29$ years $(24.3 \%)$. Also, the majority of workers injured due to accidents had work experience less than one year. The most hazardous events occurred in metal manufacturing process $(32.5 \%)$. Falling events were the most frequently reported (16\%) [9]. There was a positive relationship between worker's behavior and safety policies in workplaces $[10,2]$. The reasons for high frequency of accidents were improvidence and inappropriate safe guards [11]. Occupational events were observed in metal manufacturing, construction, textile industries, coal mining, and vehicle manufacturing, but the majority of deaths and disabilities were reported in construction industries [12].

The rate of some unintentional trauma in fatal workplace accidents was reported in agricultural services (3.8 $R^{1}$ ), construction (3.5 RR), mining (3.3 RR) and agriculture (4.4 RR) in California [13]. There are different industries in Semnan City such as mining, car industries, metal melting factories, construction industries, etc. A few epidemiological studies are conducted to evaluate the event rates in such industries. The current study aimed at describing the occurrence of accidents and determining the fatal and non-fatal accident rates in some industrial sites of Semnan.

Construction is one of the high-risk industries in Iran. Some studies show that this industry has a high accident rate and most injuries occurred due to falls. Most deaths happened after head injury. In non-fatal accidents, fracture was the most frequent injury [14, 15]. Camino López et al. (2008) reported that $27.7 \%$ of events from 1990 to 2000 occurred in 30-39 year-old workers in construction industry. The highest rate of events was reported in workers with three months to two years of work experience $(46.3 \%)$. A high percentage of events occurred due to exertion $(20.9 \%)$, followed by tools breaking $(20.5 \%)$ and downfall (10.7\%), and a low percentage of events occurred due to radiation, heat exposure, fire, and explosion (5.5\%). Most events occurred from 10 to 11 AM [16].

Mining accidents occurred due to unsafe actions. Most frequent types of non-fatal injuries were related to bone bruises and sprain. In a study in Iran on mining industries, the percentage of fatal accidents was $2.8 \%$ [17]. Agricultural accidents sometimes were very serious. The agricultural fatal accident rate in Republic of Korea was 90 per 100,000 , which is three times higher than the average global fatal accident rates [18].

\section{Materials and Methods}

The current descriptive-analytical study investigated all accidents that happened from 2014 to 2016 in the industrial sites of Semnan City, Iran. The accidents information was obtained from the Department of Labor and Social Affairs of Semnan City. The study population included 1050 workers and the data were collected using a questionnaire. The questionnaire contains items on accident history, age and occupation of the affected workers, work experience, education level, insurance coverage status, marital status, outcome of accident, and the type of shift system. Collected data were analyzed with SPSS V. 21 applying Chi-square and logistic regression tests.

\section{Results}

The Kolmogorov-Smirnov test was used to evaluate the normality of data. Populations with non-normal distribution should be analyzed by non-parametric tests. A total of 1050 workers were affected by accidents from 2014 to 2016 in Semnan. The mean and standard devia- 
tion of workers' age in non-fatal and fatal accidents were $30.58 \pm 16.14$ and $35.17 \pm 12.34$ years, respectively.

There was no significant difference in variables such as gender $(\mathrm{P}=0.83)$, working experience $(\mathrm{P}=0.64)$, and marital status $(\mathrm{P}=0.89)$ between fatal and non-fatal accidents. The result of the current study depicted that $39.2 \%$ of accidents occurred in non-skilled workers. In addition, death rate from accidents was highest in non-skilled workers (43\%) and lowest in supervisors $(11.3 \%)$. There was no significant difference among fatal accidents victims in terms of education level $(\mathrm{P}=0.92)$. There were strong and significant relationships between insurance coverage status of workers (insured vs. not insured) and fatal accidents $(\mathrm{P}=0.001)$.

Die from occupational accidents among insured ones was $8.1 \%$, while among none-insured workers was $25.3 \%$. In the current study, there was no significant difference in fatal accidents rate among investigated industries (construction, mining, rubber, and agriculture) $(\mathrm{P}=0.14)$. The findings indicated no significant difference between the fatal accidents and the year in which the accidents occurred. Although most fatal accidents occurred during the day shift, no significant relationship was observed between the type of the shift work systems and fatal accidents $(\mathrm{P}=0.75)$. Table 1 shows the distribution of fatal and non-fatal accidents based on industry type and characteristics of workers.

Logistic regression test was used to investigate the aggregating effect of the job, insurance coverage status, type of industry, and the year in which fatal accident occurred. The results indicated that all four variables had significant effects on the dependent variable. The fatal accident rate increased significantly from 2015 to 2016 in comparison with 2014 to 2015 . The rate of fatal accidents in 2015 was about 5 times higher than that of 2014 $(\mathrm{P}=0.01$, odds ratio $(\mathrm{OR}=4.76)$. Also, the rate was three times more in 2016 than $2014(\mathrm{P}=0.045, \mathrm{OR}=3.139)$.

Fatal accident rate in service sector workers was higher than that of the welding workers $(\mathrm{P}=0.006, \mathrm{OR}=7.96)$. The probability of fatal accident rates among workers without insurance was about 3.9 times higher than that of the insured ones $(\mathrm{P}=0.001, \mathrm{OR}=3.941)$. Table 2 illustrates results of logistic regression analysis and the effect of independent variables on fatal accidents.

\section{Discussion}

The current study aimed at epidemiologically investigating work-related accidents in various industries in
Semnan City. Totally, 1050 accidents happened from 2014 to 2016 in the studied sectors. The accident rate was higher in construction industry than the other ones $(n=750)$. A study conducted in Turkey showed that construction industries had high figures of general incidence and fatal accident rates [19]. Agricultural accident rate was $10 \%$. Steven reported crude accident rate of $9.3 \%$ for injured farmers [20]. The result strongly agreed with that of the current study. But, based on reports by Health and Safety Executive (HSE) regarding workplace injuries, mining had higher rate of accident than agriculture sector and construction industry [21].

The current study results indicated that nearly $73.33 \%$ of events happened during the day shift and this finding was obviously consistent with that of Mbaye et al. (2001) [22]. According to the results of the current and other studies, younger males were more susceptible to industrial events $[5,16]$. Fatal accident rates in mining and agriculture industries were significantly lower than those of construction industry. The rate of accidents was higher in males than females.

This may be due to the fact that there were fewer females in these industries and males did more risky jobs. Majority of accidents occurred for insured workers. It could be explained by the fact that non-insured employees pay more attention at least to avoid costs of accident consequences. On the other hand, fatal accidents were more prevalent among non-insured workers. It would put more pressure on this group of staffs. Based on the results, improving the insurance coverage for industrial employees decreases the number of fatal incidences, especially in mining and construction industries [19]. Improvement in the health insurance system can increase the value of welfare and medical services after accidents. In spite of the fact that the economic burden of industrial accidents is high, allocated budget for accident prevention is small $[19,23]$.

Non-skilled workers experienced more accidents than skilled ones. These workers have more fatal and nonfatal accidents in comparison with other workers due to lack of practical skills training, job experience, and job and safety knowledge. Training programs may help workers to increase their safety and health knowledge. Occupational safety and health programs can promote the performance of workers, and reduce the number of industrial accidents as well as the project costs [24, 25].

The education level of workers showed no significant relationship with fatal and non-fatal accidents. The accident rate among workers with academic education 
Table 1. The distribution of fatal and non-fatal accidents

\begin{tabular}{|c|c|c|c|c|c|c|c|c|}
\hline & Variable & Frequency & Percent & Frequency & Percent & Frequency & Percent & $\mathbf{P}^{*}$ \\
\hline \multirow{3}{*}{ 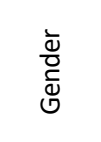 } & Male & 900 & 85.71 & 39 & 95.12 & 939 & 86.07 & \multirow{3}{*}{$0.83+$} \\
\hline & Female & 150 & 14.29 & 2 & 4.88 & 152 & 13.93 & \\
\hline & Total & 1050 & 100.00 & 41 & 100.00 & 1091 & 100.00 & \\
\hline \multirow{3}{*}{ 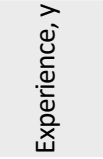 } & $<1$ & 104 & 9.90 & 6 & 14.63 & 104 & 9.53 & \multirow{3}{*}{$0.64{ }^{\dagger}$} \\
\hline & $\geq 1$ & 936 & 89.14 & 39 & 95.12 & 987 & 90.47 & \\
\hline & Total & 1040 & 99.05 & 45 & 109.76 & 1091 & 100.00 & \\
\hline \multirow{6}{*}{$\begin{array}{l}\text { 음 } \\
\frac{0}{0} \\
\frac{0}{0} \\
\frac{.}{y}\end{array}$} & Welding & 250 & 24.34 & 10 & 15.63 & 260 & 23.83 & \multirow{6}{*}{$0.718^{\dagger}$} \\
\hline & Non-skilled & 496 & 48.30 & 17 & 26.56 & 513 & 47.02 & \\
\hline & Supervisor & 142 & 13.83 & 5 & 7.81 & 147 & 13.47 & \\
\hline & Service sectors & 96 & 9.35 & 15 & 23.44 & 111 & 10.17 & \\
\hline & Other & 43 & 4.19 & 17 & 26.56 & 60 & 5.50 & \\
\hline & Total & 1027 & 100.00 & 64 & 100.00 & 1091 & 100.00 & \\
\hline \multirow{3}{*}{ 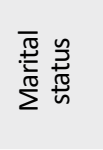 } & Married & 751 & 71.93 & 33 & 70.21 & 784 & 71.86 & \multirow{3}{*}{$0.89++$} \\
\hline & Single & 293 & 28.07 & 14 & 29.79 & 307 & 28.14 & \\
\hline & Total & 1044 & 100.00 & 47 & 100.00 & 1091 & 100.00 & \\
\hline \multirow{4}{*}{ 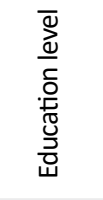 } & Illiterate & 206 & 20.08 & 19 & 29.23 & 224 & 20.53 & \multirow{4}{*}{$0.92+\dagger$} \\
\hline & High school & 684 & 66.67 & 25 & 38.46 & 709 & 64.99 & \\
\hline & University & 136 & 13.26 & 21 & 32.31 & 157 & 14.39 & \\
\hline & Total & 1026 & 100.00 & 65 & 100.00 & 1091 & 100.00 & \\
\hline \multirow{3}{*}{ 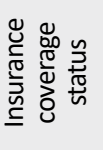 } & Insured & 844 & 81.08 & 19 & 38.00 & 863 & 79.10 & \multirow{3}{*}{$0.002 *+\dagger$} \\
\hline & Not insured & 197 & 18.92 & 31 & 62.00 & 228 & 20.90 & \\
\hline & Total & 1041 & 100.00 & 50 & 100.00 & 1091 & 100.00 & \\
\hline \multirow{5}{*}{ 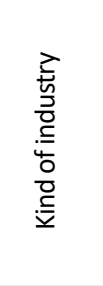 } & Construction & 709 & 70.20 & 37 & 45.68 & 746 & 68.38 & \multirow{5}{*}{$0.15^{+\dagger}$} \\
\hline & Mining and rubber industry & 97 & 9.60 & 14 & 17.28 & 111 & 10.17 & \\
\hline & Agriculture & 56 & 5.54 & 8 & 9.88 & 64 & 7.23 & \\
\hline & Other & 148 & 14.65 & 22 & 27.16 & 170 & 15.58 & \\
\hline & Total & 1010 & 100.00 & 81 & 100.00 & 1091 & 100.00 & \\
\hline \multirow{4}{*}{ 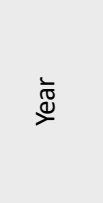 } & 2014 & 91 & 8.78 & 13 & 23.64 & 104 & 9.53 & \multirow{4}{*}{$0.2^{+\dagger}$} \\
\hline & 2015 & 84 & 8.11 & 18 & 32.73 & 102 & 9.35 & \\
\hline & 2016 & 861 & 83.11 & 24 & 43.64 & 885 & 81.12 & \\
\hline & Total & 1036 & 100.00 & 55 & 100.00 & 1091 & 100.00 & \\
\hline \multirow{5}{*}{ 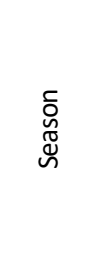 } & Spring & 75 & 7.31 & 24 & 36.92 & 99 & 9.07 & \multirow{5}{*}{$0.65+\dagger$} \\
\hline & Summer & 82 & 7.99 & 14 & 21.54 & 96 & 8.80 & \\
\hline & Fall & 83 & 8.09 & 11 & 16.92 & 94 & 8.62 & \\
\hline & Winter & 786 & 76.61 & 16 & 24.62 & 802 & 73.51 & \\
\hline & Total & 1026 & 100.00 & 65 & 100.00 & 1091 & 100.00 & \\
\hline \multirow{4}{*}{ 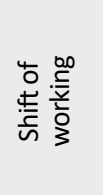 } & Day shift & 927 & 89.05 & 30 & 60.00 & 957 & 87.72 & \multirow{4}{*}{$0.8++$} \\
\hline & Afternoon shift & 96 & 9.22 & 15 & 30.00 & 111 & 10.17 & \\
\hline & Night shift & 18 & 1.73 & 5 & 10.00 & 23 & 2.11 & \\
\hline & Total & 1041 & 100.00 & 50 & 100.00 & 1091 & 100.00 & \\
\hline
\end{tabular}


Table 2. Results of logistic regression analysis

\begin{tabular}{|c|c|c|c|c|}
\hline \multirow[t]{2}{*}{ Category } & \multicolumn{2}{|c|}{ Variable } & \multirow{2}{*}{$\begin{array}{c}\text { P* } \\
-\end{array}$} & \multirow{2}{*}{$\begin{array}{c}\text { OR } \\
-\end{array}$} \\
\hline & 2014 & Reference & & \\
\hline \multirow[t]{4}{*}{ Year } & 2015 & - & $0.009 \sim 0.01$ & 4.76 \\
\hline & 2016 & - & 0.045 & 3.139 \\
\hline & Welding & Reference & - & - \\
\hline & Non-skilled workers & - & 0.227 & 2.13 \\
\hline \multirow[t]{5}{*}{ Kind of job } & Supervisor & - & 0.938 & 1.11 \\
\hline & Service sectors & - & 0.005 & 7.96 \\
\hline & Other & - & 0.005 & 8.601 \\
\hline & Construction & Reference & - & - \\
\hline & Mining and rubber industry & - & 0.32 & 0.538 \\
\hline & Agriculture & - & $0.1167 \sim 0.117$ & 0.296 \\
\hline & Other & - & $0.0049 \sim 0.005$ & 0.181 \\
\hline \multirow{2}{*}{ Insurance } & Insured & Reference & - & - \\
\hline & Not insured & - & $0.0006 \sim 0.001$ & 3.941 \\
\hline
\end{tabular}

was lower than that of the ones with other education levels. Workers with high school education had high fatal and non-fatal accident rates. One more thing, the accident rate was higher in cold seasons. It had the highest rate in winter and the lowest in summer. However, other studies depicted lowest accidents in fall and winter and highest in spring [21].

Despite the variations in findings, it may be due to working systems, as well as schedule and nature of the work. For example, Hosseinpour et al. (2017) reported lowest admission rate for road traffic accidents in motorcyclists during autumn and the highest rate during summer [26]. Industrial emergency plans are essential to prevent the accidents. Providing the first aid training program may help to prevent more accidents in industrial sites. Improvement of emergency medical services in workplaces can help the workers during the early moments of incidence. Also, employers should provide proper safety equipments for workers. The safety equipment may reduce the frequency and severity of accidents. Risk assessment methods can help to identify the root causes of accidents and define the risk control measures [27].

New macro approach to control and prevent accidents considers organizational structure and work system in the context of occupational safety [26-28]. Data gathering was difficult due to improper documentation about safety and health training programs. Majority of accidents in the developing countries are not recorded. Shift work schedule was not declared in the current study; it is suggested that future studies should declare it [29] and assess the effect of ergonomics and shift work object in safety climate [29].

\section{Conclusion}

Altogether, construction industries had the highest accident rates. Also, large numbers of accidents happened during the day shifts. Younger males were more prone to accidents caused by industrial hazards. According to the obtained results, occupational safety and health program can promote the performance of workers; and holding meetings about occupational safety and health issues with employees, stating objectives, rules and regulations, policy, and applied procedures, training and easy communications are good activators to control workrelated accidents. Both individual and organizational approaches needed to prevent accidents. 


\section{Ethical Considerations}

\section{Compliance with ethical guidelines}

The present study was conducted by paying special attention to the privacy of personal information and all the ethical codes in this regard.

\section{Funding}

This research did not receive any specific grant from funding agencies in the public, commercial, or not-forprofit sectors.

\section{Authors contributions}

All authors contributed in preparing this article.

\section{Conflict of interest}

The authors declared no conflict of interest.

\section{Acknowledgements}

The authors would like to thanks the Department of Labor and Social Affairs of Semnan for giving information.

\section{References}

[1] Azizi A, Morad Veisi F, Amirian F, Dargahi A, Mohammadi S, Poursadeghiyan M, et al. Epidemiology of lowers limb fractures in patient of Taleghani hospital in Kermanshah in 2014. Research Journal of Medical Sciences. 2016; 10(4):325-9.

[2] Poursadeghiyan M, Omidi L, Hami M, Raei M, Biglari H. Epidemiology of fatal and non-fatal industrial accidents in Khorasan Razavi Province. International Journal of Tropical Medicine. 2016; 11(5):170-4. [DOI:10.3923/ijtmed.2016.170.174]

[3] Rikhardsson PM, Impgaard M. Corporate cost of occupational accidents: An activity-based analysis. Accident Analysis \& Prevention. 2004; 36(2):173-82. [DOI:10.1016/S00014575(02)00147-1]

[4] Ebrahimi M H, Abbasi M, Khandan M, Poursadeghiyan M, Hami M, Biglari H. [Effects of administrative interventions on improvement of safety and health in workplace: A case study in an oil company in Iran (2011-2015) (Persian)]. Journal of Engineering and Applied Sciences. 2016; 11(3):346-51.

[5] Meliá JL, Mearns K, Silva SA, Lima ML. Safety climate responses and the perceived risk of accidents in the construction industry. Safety Science. 2008; 46(6):949-58. [DOI:10.1016/j. ssci.2007.11.004]

[6] Arndt V, Rothenbacher D, Daniel U, Zschenderlein B, Schuberth S, Brenner $\mathrm{H}$. Construction work and risk of occupational disability: A ten year follow up of 14474 male workers.
Occupational and Environmental Medicine. 2005; 62(8):55966. [DOI:10.1136/oem.2004.018135]

[7] Abbasi M, Zakerian A, Akbarzade A, Dinarvand N, Ghaljahi $\mathrm{M}$, Poursadeghiyan $\mathrm{M}$, et al. Investigation of the relationship between work ability and work-related quality of life in nurses. Iranian Journal of Public Health. 2017; 46(10):1404-12. [PMID] [PMCID]

[8] Sadeghain M, Ataei Farid R, Dormohammadi A, Allah Aghaei H, Rahmani A, Farhadi R, et al. Assessment of the prevalence of occupational accidents and their influential factors in an electricity distribution company during a fiveyear period. Electronic Physician Journal. 2013; 5(2):643-50. [DOI:10.14661/2013.643-650] [PMID] [PMCID]

[9] Unal HG, Gök A, Gök K. Occupational accident characteristics in Türkiye between 1997-2005. Kastamonu Eğitim Dergisi. 2008; 16(2):637-50.

[10] Mohamed S, Ali TH, Tam W. National culture and safe work behaviour of construction workers in Pakistan. Safety Science. 2009; 47(1):29-35. [DOI:10.1016/j.ssci.2008.01.003] [DOI:10.1016/j.ssci.2008.01.003]

[11] Colak B, Etiler N, Bicer U. Fatal occupational accidents in the construction sector in Kocaeli, Turkey, 1990-2001. Industrial Health. 2004; 42(4):424-30. [DOI:10.2486/indhealth.42.424]

[12] Unsar S, Sut N. General assessment of the occupational accidents that occurred in Turkey between the years 2000 and 2005. Safety Science. 2009; 47(5):614-9. [DOI:10.1016/j. ssci.2008.08.001]

[13] Loomis DP, Richardson DB, Wolf SH, Runyan CW, Butts JD. Fatal occupational accidents in a southern state. American Journal of Epidemiology. 1997; 145(12):1089-99. [DOI:10.1093/ oxfordjournals.aje.a009071]

[14] Malakouti J, Gharibi V, Jang SA, Gholami A, Koohpaei A. [An epidemiological study of accidents in a construction industry: a case-control study (Persian)]. Qom University of Medical Sciences Journal. 2013; 6(4):88-95.

[15] Bahrampour A, Nodoushan RJ, Shoaa JV. [Five-year epidemiological study and estimation of accidents distribution in construction industry workers in Yazd city by the year 2011 by applying time series model (Persian)]. Journal of Kerman University of Medical Sciences. 2009; 16(2):156-64.

[16] Camino López MA, Ritzel DO, Fontaneda I, González Alcantara OJ. Construction industry accidents in Spain. Journal of Safety Research. 2008; 39(5):497-507. [DOI:10.1016/j. jsr.2008.07.006]

[17] Malek M, Mohammadi S, Aghilinejad M, Attarchi MS, Rahimpour F, Alizade S. [Investigating the pattern of occupational accidents in Iranian miners (Persian)]. Occupational Medicine Quarterly Journal. 2011; 3(1):28-33.

[18] Takala J. Global estimates of fatal occupational accidents. Epidemiology-Baltimore. 1999; 10(5):640-6. [DOI:10.1097/00001648-199909000-00034]

[19] Ceylan H. Analysis of occupational accidents according to the sectors in turkey. Gazi University Journal of Science. 2012; 25(4):909-18.

[20] Browning SR, Truszczynska H, Reed D, McKnight RH. Agricultural accidents among older Kentucky farmers: The farm family health and hazard surveillance study. American Jour- 
nal of Industrial Medicine. 1998; 33(4):341-53. [DOI:10.1002/ (SICI)1097-0274(199804)33:43.0.CO;2-X].

[21] Davies R, Jones P. Trends and context to rates of workplace injury. Coventry: Health and Safety Executive; 2005.

[22] Mbaye I, Fall M, Sarr E, Ouatara B, Sow M. Characteristics of occupational accidents in the building industry and public works in Senegal. Dakar Médical. 2001; 46(2):121-4. [PMID]

[23] Leigh JP, Markowitz SB, Fahs M, Shin C, Landrigan PJ. Occupational accident and illness in the United States: Estimates of costs, morbidity, and mortality. Archives of Internal Medicine. 1997; 157(14):1557-68. [DOI:10.1001/ archinte.157.14.1557] [PMID]

[24] Cox S, Cox T. The structure of employee attitudes to safety: A European example. Work \& Stress. 1991; 5(2):93-106. [DOI:10.1080/02678379108257007]

[25] Kartam NA, Bouz RG. Fatalities and accidents in the Kuwaiti construction industry. Accident Analysis \& Prevention. 1998; 30(6):805-14. [DOI:10.1016/S0001-4575(98)00033-5]

[26] Hosseinpour M, Mohammadian-Hafshejani A, Esmaeilpour Aghdam M, Mohammadian M, Maleki F. [Trend and seasonal patterns of injuries and mortality due to motorcyclists traffic accidents; a hospital-based study (Persian)]. Bulletin of Emergency \& Trauma. 2017; 5(1):47-52. [PMID] [PMCID]

[27] Khandan M, Vosoughi S, Azrah K, Poursadeghiyan M, Khammar A. Decision making models and human factors: TOPSIS and Ergonomic Behaviors (TOPSIS-EB). Management Science Letters. 2017; 7(2):111-8. [DOI:10.5267/j. msl.2016.11.008]

[28] Khandan M, Aligol MH, Shamsi M, Poursadeghiyan M, Biglari H, Koohpaei A. Occupational health, safety, and ergonomics challenges and opportunities based on the organizational structure analysis: A case study in the selected manufacturing industries in Qom Province, Iran, 2015. Annals of Tropical Medicine and Public Health. 2017; 10(3):606-11. [DOI:10.4103/ATMPH.ATMPH_110_17]

[29] Abbasi M, Dehghan SF, Madvari RF, Mehri A, Ebrahimi $\mathrm{MH}$, Poursadeghiyan $\mathrm{M}$, et al. Interactive effect of background variables and workload parameters on the quality of life among nurses working in highly complex hospital units: A cross-sectional study. Journal of Clinical and Diagnostic Research. 2019; 13(1):LC8-13. 
This Page Intentionally Left Blank 